\title{
MACHINABILITY OF SPRING SteEL 42SiCR
}

\author{
Ondrej Marsalek, Jaroslava Fulemova, \\ Tomas Zatloukal \& Simon Syrovatka
}
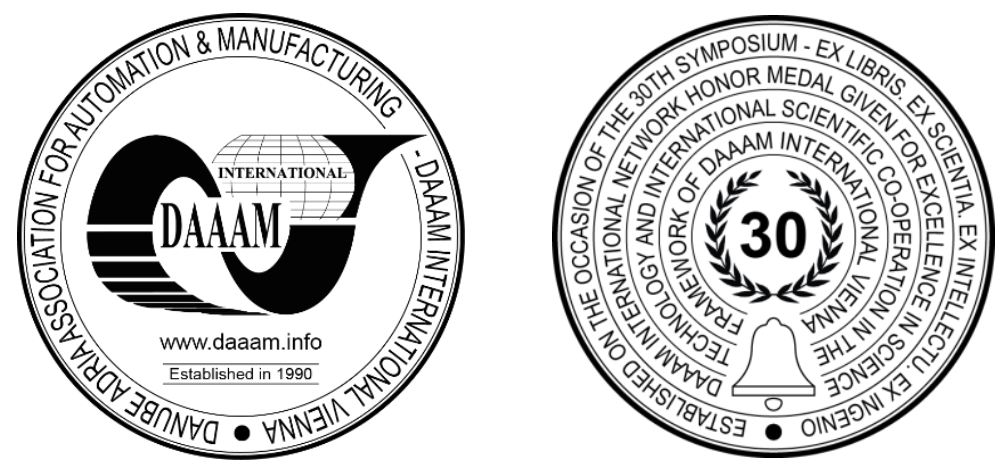

This Publication has to be referred as: Marsalek, O[ndrej]; Fulemova, J[aroslava]; Zatloukal, T[omas] \& Syrovátka, S[imon] (2021). Machinability of Spring Steel 42SiCr, Proceedings of the 32nd DAAAM International Symposium, pp.0433-0438, B. Katalinic (Ed.), Published by DAAAM International, ISBN 978-3-902734-33-4, ISSN 1726-9679, Vienna, Austria

DOI: $10.2507 / 32$ nd.daaam.proceedings.063

\begin{abstract}
Spring steels represent an important group of stainless structural steels. Thanks to their mechanical properties and especially their resistance to alternating, ie static and dynamic stresses are used for springs, mainly in the automotive industry. With constantly evolving technologies and tools, new materials and processes of heat treatment are also being developed. The aim of this work is to determine the machinability and its classification of spring steel $42 \mathrm{SiCr}$, where one set of samples was heat-treated by conventional hardening and tempering and the other set of samples according to the Q-P process (Quenching and Partitioning Process) with extended residence time at redistribution temperature to obtain high strength while maintaining ductility. An experiment was performed in which the machinability of the tested spring steel samples was determined. The result of the experiment are graphs determining wears versus times measurement, graphs determining Taylor equation and a table with the determined machinability classes.
\end{abstract}

Keywords: steel 42SiCr; machinability; tool-life; flank wear

\section{Introduction}

With constantly evolving technologies and tools, new materials and processes for heat treatment are also being developed. Such materials, which by their chemical composition, physical and mechanical properties best suit certain machine components, thanks to which their functionality, efficiency, safety and other aspects will be better fulfilled. Due to the appropriate choice of heat treatment, it is possible to further improve the properties of the material. Heat treatments usually serve to enhance one particular property of a material. For example, hardening to increase hardness for parts requiring good abrasion resistance, or annealing to increase toughness for dynamically stressed parts.

Because it would be best to have materials with high strength and hardness and sufficient toughness, heat treatment techniques are therefore being developed to meet these properties. These properties are suitable, for example, for spring steels, which are used for these dynamically stressed components. However, high strength and ductility affect machinability. Machinability is important for a complete description of new material. Thanks to it, it is possible to determine suitable cutting conditions, which will increase the productivity of the cutting process and improve the quality of the surface of the part. 
Machinability of a material is a complex technological property expressing the efficiency with which a material can be processed by machining technology at low costs under given technological conditions. This is one of the most important features in terms of machining technology. The machinability of a given material is difficult to define by the absolute value of a quantity. This is the overall influence of mechanical and physical properties (strength, hardness, thermal conductivity of the material), chemical composition (carbon content, alloying elements), the microstructure of the material, the heat treatment used and the method of manufacturing the semi-finished product. However, it cannot only be related to the material being machined, as it also depends on the cutting process and the properties of the machining tool. That is, on the method of machining, cutting environment, cutting conditions, tool material and its cutting ability, as well as tool geometry and other characteristics of the cutting proces [1].

The work deals with the determination of machinability and classification of spring steel $42 \mathrm{SiCr}$ during various heat treatments. These heat treatments are conventional quenching with subsequent tempering and a $\mathrm{Q}-\mathrm{P}$ process with an extended residence time at the redistribution temperature, which ensures a suitable strength-to-ductility ratio [2]. The determination of machinability will be used to determine suitable cutting conditions, which will make it possible to machine this steel more efficiently.

\section{Test material $42 \mathrm{SiCr}$}

Within the Department of Materials and Engineering Metallurgy, steel with the designation 42SiCr was developed in cooperation with other workplaces. It is an experimental high-strength low-alloy steel. The main alloying elements of this steel are carbon, silicon, manganese and chromium. More detailed chemical composition is contained in Table 1. By default, the $42 \mathrm{SiCr}$ material has a tensile strength $\mathrm{Rm}$ of $980 \mathrm{MPa}$, a hardness of $281 \mathrm{HV} 10$, which is a Vickers hardness with a load of 10 kiloponds, and a ductility A of about 15.4\% [3]. By suitable heat treatment, it is possible to increase the strength and hardness limit, but at the expense of reducing the ductility.

\begin{tabular}{|c|c|c|c|c|c|c|c|}
\hline $\mathbf{C}[\%]$ & $\mathbf{S i}[\%]$ & $\mathbf{M n}[\%]$ & $\mathbf{C r}[\%]$ & $\mathbf{S}[\%]$ & $\mathbf{P}[\%]$ & $\mathbf{M o}[\%]$ & $\mathbf{N b}[\%]$ \\
\hline 0.43 & 2.03 & 0.59 & 1.33 & 0.004 & 0.009 & 0.03 & 0.03 \\
\hline
\end{tabular}

Table 1. Chemical composition of $42 \mathrm{SiCr}$ steel [3]

A total of two different samples were provided to the test material, which differed from each other in their chemical properties, which are the tensile strength $\mathrm{Rm}$, hardness and ductility A. The chemical composition of all samples was the same. Different chemical properties of the samples were achieved using different types of heat treatment or different conditions during certain heat treatment. The semi-finished products of the samples were round bars with a diameter of $20 \mathrm{~mm}$.

The types of heat treatment were:

- Hardening and tempering

- $\mathrm{Q}-\mathrm{P}$ process with extended residence time at redistribution temperature

During quenching and tempering, the samples were heated in an oven to $950{ }^{\circ} \mathrm{C}$ for 21 minutes, followed by quenching in water to room temperature, then further heating in an oven to $250{ }^{\circ} \mathrm{C}$ for 10 minutes, and finally free cooling to room temperature. During the $\mathrm{Q}-\mathrm{P}$ process with an extended residence time at the redistribution temperature, the samples were heated in an oven to $950^{\circ} \mathrm{C}$ for 21 minutes, followed by quenching in water for 5 seconds. Next, immersion the samples in a salt bath at a temperature of $200{ }^{\circ} \mathrm{C}$.

Then heat in an oven to $250{ }^{\circ} \mathrm{C}$ for 20 minutes and then cool to room temperature. The $\mathrm{Q}-\mathrm{P}$ process is a process whose main goal is to stabilize untransformed austenite with carbon precipitated from supersaturated martensite and to suppress the formation of carbides by suitable alloying [2]. The following table shows the values of mechanical properties for the material $42 \mathrm{SiCr}$ in the basic state, in the state after hardening and tempering and in the state after the $\mathrm{Q}-\mathrm{P}$ process.

\begin{tabular}{|c|c|c|c|}
\hline State & Tensile strength $\boldsymbol{R}_{\boldsymbol{m}}[\mathrm{MPa}]$ & Hardness HV 10 & Ductility [\%] \\
\hline Basic & 980 & 281 & 15.4 \\
\hline Hardening and Tempering & 2095 & 629 & 11.3 \\
\hline Q-P process & 1960 & 575 & 15.7 \\
\hline
\end{tabular}

Table 2. Mechanical properties of $42 \mathrm{SiCr}$ steel and tested samples 


\section{Method of determining machinability}

A long-term machinability test was chosen to determine machinability. Its criterion is the value of the cutting speed and it can be done by turning or milling. The long-term test is performed under the same cutting conditions as during actual machining. Due to this fact, the results it shows are credible and corresponding to the facts. It is considered to be a basic test of machinability, according to which the objectivity of other tests is assessed. The principle is that the tool durability during machining of the tested material is determined using an experiment, which is then compared with the tool durability obtained during machining of the reference materiál [5].

It is desirable to perform a long-term machinability test under normative conditions. These mainly include the machining tool and the cutting conditions. This is to increase the reliability and comparability of test results, regardless of where and by whom the test was performed. Therefore, the experiment was designed according to the international standard ISO 3685. This international standard contains recommendations aimed at unifying procedures to increase the reliability and comparability of test results when comparing cutting tools, workpiece materials, cutting conditions or cutting fluids. To achieve these objectives as closely as possible, the standard includes and specifies in detail the recommended reference materials and the working conditions to be observed [6].

\section{Experiment}

The experiment was performed on a CNC lathe EMCO Maxxturn 25, which best met the defined conditions of the standard. The intensity of the wear was measured on a KEYENCE VHX-6000 digital microscope with a magnification of up to 200×. According to the specifications of the ISO 3685 standard, a tool with the designation SSRCL 1212 F09 with a cutting insert SCMT 09T304-14 was chosen. The following figure (Fig. 1) shows a view of the working space of the machine. The picture shows a test sample that is clamped in a collet and support tip and a cutting tool.

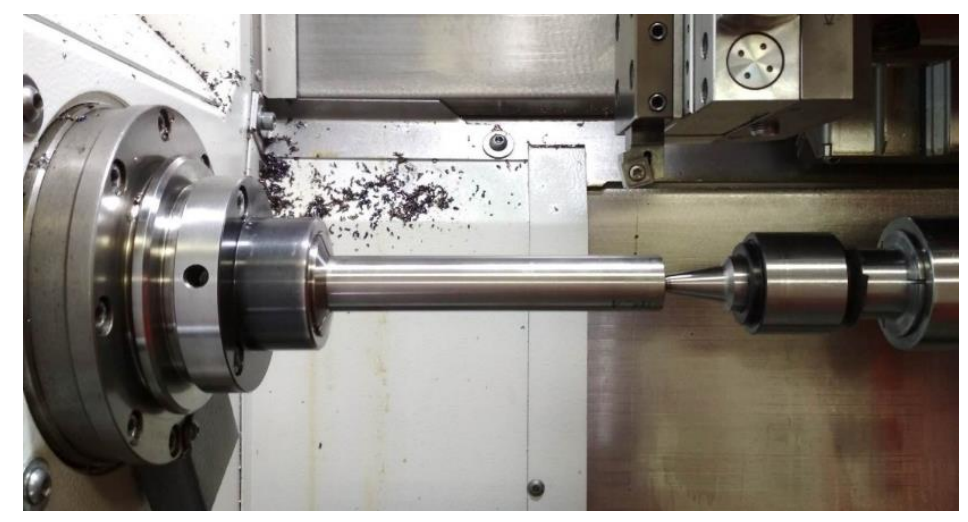

Fig. 1. View into the working space of the machine during the test of machinability of $42 \mathrm{SiCr}$ steel

Before the start of each measurement, and every time the cutting edge and the cutting speed changed, a picture of a new blade was taken on a digital microscope, which can be seen in the following figure (Fig. 2). After a picture of the new cutting edge was taken, the insert was clamped in the tool holder and the cutting conditions were defined in the machine program. These conditions were selected from the ISO standard and verified by pre-experiment. The following were selected as the default cutting conditions:

- Cutting speed $\mathrm{v}_{\mathrm{c}}=70 \mathrm{~m} / \mathrm{min}$

- Feed $\mathrm{f}=0.1 \mathrm{~mm} / \mathrm{rev}$

- Depth of cut $\mathrm{a}_{\mathrm{p}}=0.6 \mathrm{~mm}$

- Flank wear criterium $\mathrm{VB}_{\text {crit }}=0.3 \mathrm{~mm}$

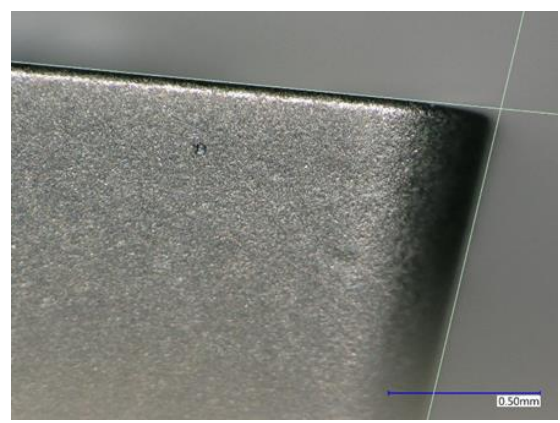

Fig. 2. New cutting edge 
After machining the first layer, the insert was removed from the holder, cleaned and then measured on a microscope. The VBB max value was measured on the flank [4]. The measurement on the microscope was performed by plotting the measuring dimension from the auxiliary line defining the original cutting edge, which was used to measure the VBB max wear. The following figure shows the development of the flank wear under the conditions given above for samples heattreated by the Q-P process. The figure shows the cutting edge from left to right after the first, third and ninth crossings for which the VBcrit value has been reached.
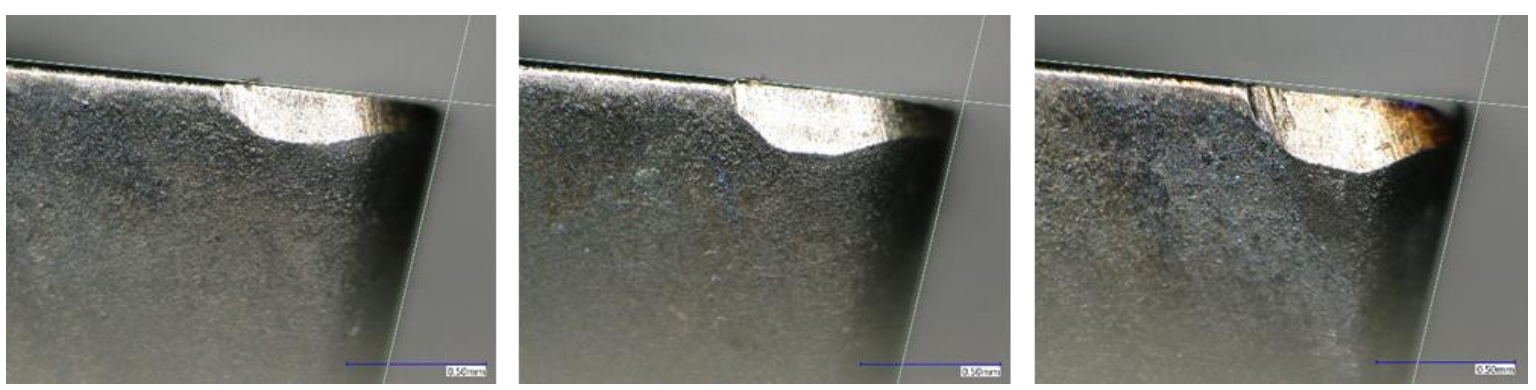

Fig. 3. Development of flank wear at $\mathrm{v}_{\mathrm{c}} 70 \mathrm{~m} / \mathrm{min}$ for sample after Q-P proces

This procedure was the same for all selected cutting speeds. According to the standard, it was necessary to select at least three values of the cutting speed. Cutting speeds were increased according to a standard defined index. All measured values were recorded in a table. The values of the diameter $\mathrm{D}$ and the cutting length $\mathrm{L}$ are needed to calculate the time in cut $\mathrm{t}$ and from that of the total time in cut $\Delta \mathrm{t}$ which is necessary to compile a graph of determining wears versus times measurement.

\begin{tabular}{|c|c|c|c|c|}
\hline Cut No. & $\mathbf{V B}_{\mathbf{B}} \mathbf{m a x} .[\boldsymbol{\mu m}]$ & $\mathbf{D}[\mathbf{m m}]$ & $\mathbf{L}[\mathbf{m m}]$ & $\boldsymbol{\Delta t}[\mathbf{m i n}]$ \\
\hline 1. & 140 & 18.8 & 110 & 0.928 \\
\hline 2. & 180 & 17.6 & 109.7 & 1.795 \\
\hline 3. & 200 & 16.4 & 109.7 & 2.602 \\
\hline 4. & 230 & 15.2 & 109.4 & 3.348 \\
\hline 5. & 240 & 14 & 109.4 & 4.036 \\
\hline 6. & 260 & 12.8 & 109.1 & 4.662 \\
\hline 7. & 290 & 11.6 & 109.1 & 5.230 \\
\hline 8. & 300 & 10.4 & 108.8 & 5.738 \\
\hline
\end{tabular}

Table 3. Measured and calculated values $\mathrm{VB}_{\mathrm{B}} \max$. and $\Delta \mathrm{t}[8]$

\section{Evaluation of the experiment}

From the values of flank wear VBB max. and total cutting time $\Delta \mathrm{t}$, it is possible to construct a graph showing the dependence of VBB flank wear on the cutting time t. After plotting all points, a curve can be constructed showing the course of the flank wear for the evaluated cutting speed. This was done for all selected cutting speeds, which were $\mathrm{v}_{\mathrm{c} 1}=70 \mathrm{~m} / \mathrm{min}, \mathrm{v}_{\mathrm{c} 2}=78 \mathrm{~m} / \mathrm{min}, \mathrm{v}_{\mathrm{c} 3}=87 \mathrm{~m} / \mathrm{min}$ and $\mathrm{v}_{\mathrm{c} 4}=97 \mathrm{~m} / \mathrm{min}$. At the highest cutting speed, the VBcrit value was reached after the first cut. The resulting overall graph of VBB max versus $t$ is shown below in the figure (Fig. 4.).

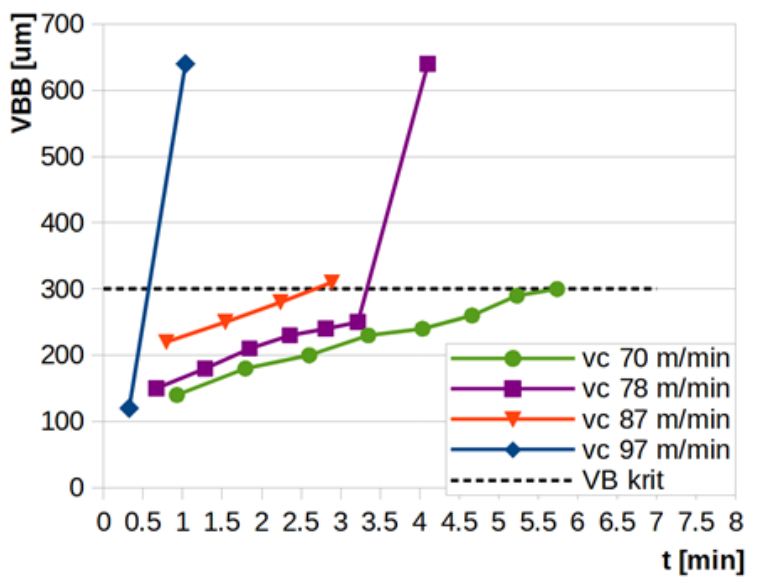

Fig. 4. Graph determining of flank wear versus time 
From this graph, it was possible to determine tool life for certain cutting speeds. This was followed by the construction of a graph expressing a graphical representation of Taylor's equation. This graph can be seen in figure (Fig. 5.). From the graph in figure (Fig. 5.), the Taylor equation was determined and from it the machinability index, which is needed to determine the machinability class. The cutting speed vc1 was not considered in the graph because it achieved a tool-life of less than $1 \mathrm{~min}$. Three cutting speeds values can be used to properly evaluate the experiment. The experiment also had to be performed on a reference material defined by the standard, which is carbon steel with the designation C45 [6].

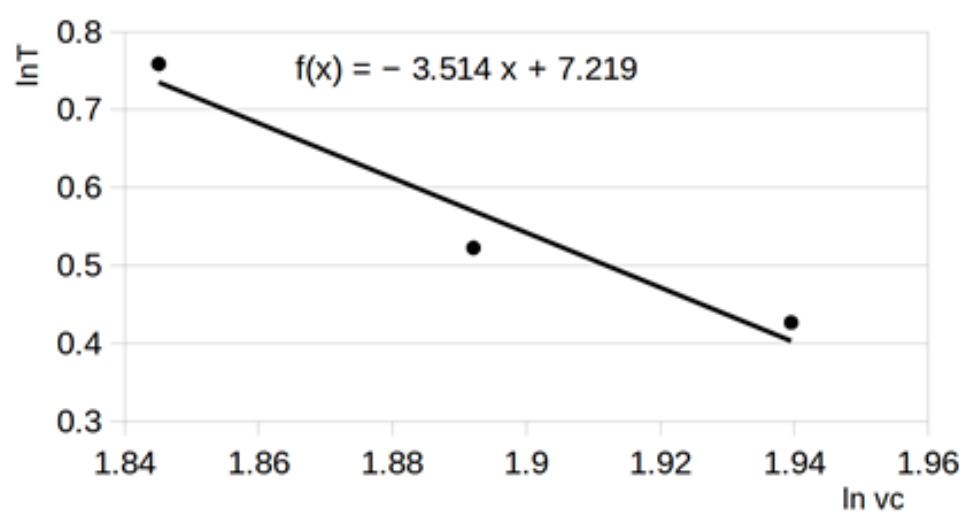

Fig. 5. Graph of dependence of durability on cutting speed

The following table shows the resulting machinability classes for the 42SiCr spring steel test samples heat treated by hardening and tempering and the Q-P process. The reference material has a machinability class of $14 \mathrm{~b}$, so both test specimens have been found to have poorer machinability because they have a lower machinability class [7].

\begin{tabular}{|c|c|}
\hline Test sample & Machinability class \\
\hline Hardened and tempered & $12 \mathrm{~b}$ \\
\hline Q-P process & $12 \mathrm{~b}$ \\
\hline
\end{tabular}

Table 4. Specified machinability classes of test samples

\section{Conclusion}

This work aimed to determine the machinability and classification of various heat-treated test samples of $42 \mathrm{SiCr}$ spring steel. The machinability of the test samples was determined using a long-term machinability test, which was selected for reasons of the credibility of the measured results. The long-term machinability test was performed according to the ISO 3685 standard to increase the reliability and comparability of the results. The standard deals with tool-life testing with single-point turning tools. Experimental designs were performed from the knowledge gained from the standard. Furthermore, the types of cutting tools and cutting conditions were determined according to the characteristics specified by the standard and, last but not least, the methods of clamping the semi-finished products and the test procedures. The designs were followed by the actual implementation of experiments to determine machinability. To completely determine the machinability of the tested materials, it was necessary to perform a long-term machinability test for the reference steel marked $\mathrm{C} 45$. The machinability class $12 \mathrm{~b}$ was issued for the tested samples, which indicates slightly worse machinability than that of the reference material.

This finding was very surprising because the chemical composition of the 42SiCr spring steel and the mechanical properties of the test specimens obtained by the various heat treatments indicated that the machinability would be significantly worse. In the future, this experiment needs to be repeated with a higher number of test specimens. It is assumed that these results were obtained due to the small number of test samples. With a larger amount of test material, a more thorough long-term machinability test will be performed, which will probably show that the machinability of the heat-treated $42 \mathrm{SiCr}$ steel samples is indeed much worse.

\section{Acknowledgments}

This article was created under the project SGS-2019-008: Research and Development for Innovation in the Field of Manufacturing Technology - Machining Technology III.

\section{References}

[1] Qehaja, N. E.; Salihu, A. H.; Zeqiri, H. M.; Osmani. H. \& Zeqiri, F. (2012). Machinability of metals, methods and practical application. Proceedings of the 23rd DAAAM International Symposium, Volume 23, No.1, ISSN 2304- 
1382 ISBN 978-3-901509-91-9, CDROM version, Ed. B. Katalinic, Published by DAAAM International, Vienna, Austria, EU, 2012

[2] Bublikova, D.; Jenicek, S.; Jirkova, H.; \& Stehlik, A. (2018). Heat Treatment of Closed-Die Forgings of Low-Alloy AHSS Steels, Proceedings of the 29th DAAAM International Symposium, pp.0714-0718, B. Katalinic (Ed.), Published by DAAAM International, ISBN 978-3-902734- 20-4, ISSN 1726-9679, Vienna, Austria DOI: 10.2507/29th.daaam.proceedings.103

[3] Janda, T.; Jirkova, H. \& Jenicek, S. (2018). Comparing Properties of the 42SiCr Steel After Conventional Heat Treatment and QP Processing, Proceedings of the 29th DAAAM International Symposium, pp.1164-1167, B. Katalinic (Ed.), Published by DAAAM International, ISBN 978- 3-902734-20-4, ISSN 1726-9679, Vienna, Austria DOI: $10.2507 / 29$ th.daaam.proceedings. 167

[4] Zeqiri, H. M.; Qehaja, N. E.; Zeqiri, F.; Salihu, A. H. \& Osmani, H. (2012). Research of flank wear in turning of steel CK60. . Proceedings of the 23rd DAAAM International Symposium, Volume 23, No.1, ISSN 2304-1382 ISBN 978-3-901509-91-9, CDROM version, Ed. B. Katalinic, Published by DAAAM International, Vienna, Austria, EU, 2012

[5] Rejshekhar, L.; Prasad, K. \& Mohankumar, G. C. (2014). An Experiment Investigation on Machinability Studies of Steels by Face Turning. 3rd Internacional Conference on Materials Processing and Characterisation (ICMPC 2014). [Online]. Available: https://core.ac.uk/download/pdf/82785849.pdf

[6] International Standard ISO 3685. Tool-life testing with single-point turning tools. 2nd edit. Switzerland: International Organization for Standardization, 1993.

[7] Švarc, V. (2011). Obrobitelnost materiálů skupiny b - Machinability of group materials b. Master thesis. Department of Machining technology. University of West Bohemia. Pilsen. Czech Republic.

[8] Maršálek, O. (2020). Obrobitelnost pružinové oceli 42SiCr - Machinability of spring steel 42SiCr. [Online]. Available: https://dspace5.zcu.cz/bitstream/11025/41588/1/DP_Marsalek_Ondrej.pdf 